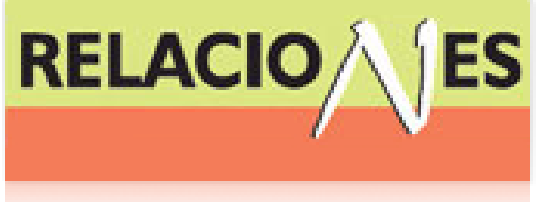

Relaciones. Estudios de historia y sociedad ISSN: 0185-3929

relacion@colmich.edu.mx

El Colegio de Michoacán, A.C

México

Yáñez Andrade, Juan Carlos

El trabajo en el debate panamericano (1923-1936)

Relaciones. Estudios de historia y sociedad, vol. XXXV, núm. 138, 2014, pp. 45-72

El Colegio de Michoacán, A.C

Zamora, México

Disponible en: http://www.redalyc.org/articulo.oa?id=13731369003

- Cómo citar el artículo

- Número completo

- Más información del artículo

Página de la revista en redalyc.org

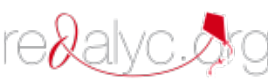

Sistema de Información Científica

Red de Revistas Científicas de América Latina, el Caribe, España y Portugal Proyecto académico sin fines de lucro, desarrollado bajo la iniciativa de acceso abierto 


\title{
El trabajo en el debate panamericano (1923-1936)
}

\author{
Juan Carlos Yáñez Andrade*
}

UNIVERSIDAD VIÑA DEL MAR, CHILE

El presente artículo aborda el proyecto presentado por la delegación mexicana a la Conferencia Panamericana de 1933 de creación de un Instituto Interamericano del Trabajo. Se analiza el panamericanismo y las instancias que ofreció para el análisis de los problemas sociales y laborales desde una perspectiva continental, especialmente desde la Conferencia Panamericana de 1923. Al encuentro de las posiciones que la Organización Internacional del Trabajo (отт) había ganado en la región, el artículo se plantea la posibilidad que entrega un capítulo desconocido de la historia laboral de los ańos treinta para repensar el Estado de Bienestar latinoamericano.

(Panamericanismo, conferencias panamericanas, trabajo, Instituto Interamericano, OIT)

\section{INTRODUCCIÓN}

T os pocos trabajos que han estudiado el panamericanismo han abordado sus aspectos políticos e ideológicos, dejando de lado los aportes que las conferencias panamericanas (CP) ofrecieron al conocimiento de los problemas sociales y laborales del continente. ${ }^{1}$ Desarrolladas desde 1889, ofrecieron a partir de 1923 una instancia de debate incorporando nuevos dominios y temáticas. Por su parte, la oIT fue creada en 1919 en el contexto del Tratado de Versalles con

\section{*jyanez@uvm.cl}

${ }^{1}$ Parte de esa bibliografía será citada en este artículo. Una excepción de aquella apreciación es el artículo de Vanesa Teitelbaum, "La política laboral en la viI conferencia panamericana", en Carlos Marichal, México y las Conferencias Panamericanas, México, Secretaría de Relaciones Exteriores, 2002. 
el afán de promover la paz social fundada en el reconocimiento de los derechos de los trabajadores. ${ }^{2}$ Luego de años de lento acercamiento a la región y de dominio incontestable en la promoción de la legislación del trabajo, la institución de Ginebra se enfrentó a la acción de la Unión Panamericana (UPAM). De esta forma, cuando la delegación de México presentó en 1933 el proyecto de un Instituto Interamericano del Trabajo (IIT), la oIT vio en su creación un ataque directo a sus intereses. Las dificultades en el establecimiento del Instituto y la dinámica de cambios que sufrió el continente hacia mediados de la década de 1930, explican en parte que el proyecto aprobado en la CP de 1933 no fuera posteriormente considerado. Sin embargo, creemos que el estudio del fracasado intento de creación del IIT nos ofrece la posibilidad de interpretar la historia laboral latinoamericana en una perspectiva internacional, donde el proceso de construcción de la institucionalidad sociolaboral supuso una relación compleja entre Estados, técnicos, legisladores y organismos internacionales, en este caso particular la UPAM y la OIT, proporcionando nuevos antecedentes históricos que nos permiten complementar las explicaciones centradas exclusivamente en la acción del Estado o de la legislación nacional.

El objetivo central de este estudio es trazar el recorrido histórico del proyecto de creación del IIT, como parte de la discusión sobre la relación Estado-capital-trabajo que se instaló en el continente en los

\footnotetext{
${ }^{2}$ Existe una amplia bibliografía sobre la ort que es imposible citar en este artículo. Solo a modo de referencia, Jean-Michel Bonvin, L'Organisation internationale du travail, París, PUF, 1998; Gerry Rodgers, Lee Swepston, Eddy Lee y Jasmien van Daele, L'orT et la quête de justice sociale, 1919-2009, Ginebra, OIT, 2009 ; Jasmien Van Daele y otros, ILO Histories : Essays on the International Labour Organization and Its Impact on the World during the Twentieth Century, Berne, Peter Lang, 2010; Sandrine Kott, "Les organisations internationales, terrains d'étude de la globalisation. Jalons pour une approche socio-historique”, Critique Internationale, núm. 52, marzo 2011, 9-16; Paul-André Rosental, "Géopolitique et État-Providence. Le BIT et la politique mondiale des migrations dans l'entre-deux-guerres", Annales. Histoire, Sciences Sociales, núm. 1, 2006, 99 134; Isabelle Lespinet-Moret y Vincent Viet, dir., L'Organisation internationale du travail. Origine, développement, avenir, Rennes, Presses Universitaires de Rennes, 2011; Alya Aglan, Olivier Feiertag y Dzovinar Kévonian, dir., Humaniser le travail. Régimes économiques, régimes politiques et Organisation internationale du travail (1929-1969), Bruxelles, Peter Lang, 2011.
} 
años treinta y que tuvo como denominador común establecer un diagnóstico, planificación e implementación de políticas sociolaborales que garantizaran una cohesión social.

Para ello, hemos tenido a disposición el archivo de la oIT, particularmente los fondos de Albert Thomas y de Moisés Poblete, las actas de las conferencias internacionales del trabajo y de las conferencias americanas del trabajo, las actas de los congresos panamericanos y folletería del Departamento de Trabajo de México, lo cual en su conjunto nos ha permitido vincular las escalas nacionales, continentales e internacionales en lo que se refiere a la discusión del proyecto del IIT y su posterior rechazo en la Conferencia Americana del Trabajo de 1936, efectuada en Santiago de Chile.

\section{CONTEXTO HISTÓRICO: EL PANAMERICANISMO}

Estados Unidos a fines del siglo XIX se lanzó a la conquista de nuevos mercados y áreas estratégicas, aspectos propicios para la expansión de su economía y consolidación como primera potencia mundial. América Latina aparecía como un territorio natural para la expansión norteamericana, concebido como mercado consumidor y proveedor de materias primas a bajo precio. En este contexto, el panamericanismo debe ser entendido como una doctrina promovida por los Estados Unidos, que bajo los principios de la cooperación y de la paz internacional -dejando de lado la antigua Doctrina Monroe- buscaba la penetración de sus propios intereses políticos y comerciales en el continente.

La primera etapa de acercamiento de los Estados Unidos a la región comenzó bajo la presidencia de Chester Arthur (1881-1885), quien envió misiones a América Latina con el fin de avanzar en una alianza comercial. ${ }^{3}$ Luego el secretario de estado James Blaine obtuvo del Congreso la autorización para la reunión de la Primera CP, inaugurada en Washington el 1 de octubre de 1889. Entre los temas abordados estuvieron el establecimiento de una unión aduanera, de

${ }^{3}$ Para un temprano estudio sobre el tema véase Ernesto Quesada, La evolución del panamericanismo, Buenos Aires, Talleres Gráficos del Ministerio de Agricultura de la Nación, 1919, 40. 
una moneda común para las transacciones comerciales, la adopción de un sistema uniforme de pesos y medidas y la formulación de un plan de arbitraje para las disputas interamericanas. ${ }^{4}$

La Oficina de Repúblicas Americanas, que luego sería conocida como UPAM, fue creada como órgano ejecutivo permanente, con funciones iniciales de coordinación comercial. Su sede estaba en Washington y bajo la supervisión del Departamento de Estado de los Estados Unidos, era su presidente el secretario de Estado de ese país. Su Consejo Ejecutivo estaba constituido por los representantes diplomáticos acreditados delante de la Casa Blanca. A la UPAM se le agregaron las agencias responsables de la cooperación y la realización de investigaciones. En el curso de los años las CP desplazaron la discusión puramente comercial para avanzar en un conjunto de materias, algunas de las cuales eran parte de la agenda internacional del gobierno de los Estados Unidos. A partir de la II CP (1901), las políticas culturales se incorporaron a la discusión, con la creación de un catálogo de obras americanas, el intercambio de publicaciones entre los países y la creación de una biblioteca especializada en temáticas de integración regional. ${ }^{5}$ Las comunicaciones del continente fueron también promovidas con la construcción de un ferrocarril y de una ruta panamericana. En fin, en torno de las políticas de salud y de seguridad social se promovió la creación de una Oficina Panamericana de la Salud en 1910.

Ahora, la estructura de la UPAM, así como su dependencia de la política de los Estados Unidos, provocaron los primeros cuestionamientos al panamericanismo de parte de algunos países. En 1910, en la CP de Buenos Aires, se aprobó la incorporación al Consejo de la UPAM de delegados de aquellos países que no tenían representación diplomática en los Estados Unidos, permitiendo con ello disminuir el control que el Departamento de Estado de ese país ejercía en el Consejo de la institución.

${ }^{4}$ Miguel Ángel Fernández, “I Conferencia Panamericana (Washington, 1889-1890). Prolegómenos para un Derecho Internacional Americano”, en Carlos Marichal, México y las Conferencias Panamericanas..., op. cit.

${ }^{5}$ Actas y documentos. Segunda Conferencia Panamericana, México, Tipografía de la Oficina Impresora de Estampillas, 1902. 
Luego de la Primera Guerra Mundial (1914-1918), los Estados Unidos pasaron a dominar no solamente la política y el comercio regional, sino que desplazaron también a las potencias europeas como principal inversor de capitales. ${ }^{6}$ Entre 1913 y 1929, la actividad comercial entre América Latina y los Estados Unidos aumentó considerablemente. Por ejemplo, en 1929, 34 \% de la producción de la región era exportada hacia los Estados Unidos (con un fuerte dominio de México y de América Central, de 70 \%) y la importación alcanzaba $39 \%$ del total de sus importaciones, con el desequilibrio comercial evidente en favor del país del norte. ${ }^{7}$ Las inversiones de los Estados Unidos en América Latina se desarrollaron de 1,500 millones de dólares en 1924 hasta los 3,000 millones en 1929, antes de la crisis. ${ }^{8}$ Las principales inversiones se orientaron a las comunicaciones y los norteamericanos controlaban totalmente, hacia fines de la década de 1920, la producción eléctrica, la telefonía y el telégrafo. La General y la Ford Motors instalaron plantas de ensamblaje en Argentina, Brasil, Uruguay y México. Mientras que los bancos City National y Chase abrieron filiales en la mayoría de los países del continente. ${ }^{9}$ Aunque la crisis económica de 1929 afectó el comercio y la inversión, ambos aspectos se recuperaron en el curso de la década de $1930 .{ }^{10}$

En términos de relaciones políticas la primera administración de Franklin D. Roosevelt (1933-1937) promovió la política de "buen vecino". ${ }^{11}$ Esta política consistió en la no intervención en los asuntos latinoamericanos y en poner fin al uso de la fuerza. Ahora, este cambio en la política exterior de los Estados Unidos se explica, según la

"Víctor Bulmer-Thomas, “Las economías latinoamericanas, 1929-1939”, en Leslie Bethell, Historia de América Latina, vol. 11, cap. 1, Barcelona, Editorial Crítica, 1997.

${ }^{7}$ Víctor Bulmer-Thomas, La historia económica de América Latina desde la independencia, México, FCE, 1998, 189-190.

${ }^{8}$ Robert Freeman Smith, "América Latina, los Estados Unidos y las potencias europeas, 1830-1930", en Leslie Bethell, Historia de América Latina, op. cit., vol. 7, capítulo 3, 98.

${ }^{9}$ Ibid., 99-100.

${ }^{10}$ Angus Maddison, Dos crisis: América y Asia. 1929-1938 y 1973-1983, México, FCE, 1988, 17.

${ }^{11}$ Robert Dallek, Franklin D. Roosevelt and American Foreign Policy, 1932-1945, Nueva York, Oxford University Press, 1995; Irwin F. Gellman, Good Neighbor Diplomacy: United States Policies in Latin America, 1933-1945, Baltimore, John Hopkins University Press, 1979. 
historiografía, al menos por dos razones. Primero, frente al nuevo orden mundial de la década de 1930 (el crecimiento del totalitarismo, la crisis de preguerra, entre otros aspectos) los Estados Unidos tenían la necesidad de reforzar su presencia en la región, a partir de una nueva política que pusiera en el centro de su acción el sistema de cooperación interamericana y la defensa hemisférica frente a la posibilidad de una guerra mundial. Segundo, los Estados Unidos se transformaron, en el transcurso de los treinta, en actores dominantes de la actividad comercial, en detrimento de las naciones europeas, por lo tanto, renunciaron a la tutela militar directa a cambio de la instauración de regímenes leales a la política exterior americana, en la mayoría de los casos dictaduras militares. Esta política de "buen vecino" tendrá su expresión concreta en la CP de Montevideo en 1933, donde la delegación de los Estados Unidos se comprometió a desarrollar una política continental consistente en renunciar a la intervención en los asuntos internos de otro Estado. Consecuente con ello, en 1934, las tropas norteamericanas se retiraron de Cuba - con la excepción de una base militar en Guantánamo- y de Haití, donde permanecían desde 1915.

El papel creciente de los Estados Unidos en América Latina no pasó desapercibido por la OІт y su primer director Albert Thomas. ${ }^{12}$ Aunque no hay un acuerdo historiográfico sobre los intentos de los Estados Unidos de minar el esfuerzo de unificación de la Sociedad de Naciones (SDN), el hecho de que el país del norte no se hubiese adherido a la SDN, y por lo tanto no formara parte de la OIT, no favorecía el liderazgo de la institución de Ginebra en el continente. En concreto, un informe del corresponsal español de la ort, Fabra Ribas, mostraba el interés de los Estados Unidos en promover durante la v CP de Santiago de Chile (1923) una SDN americana. ${ }^{13}$ Si bien últimos estudios históricos han indicado que los Estados Unidos no

${ }^{12}$ Yannik Wehrli y Fabián Herrera, “Le BIT et l'Amérique Latine durant l'entre-deuxguerres: problèmes et enjeux”, en Isabel Lespinet-Moret y Vincent Viet, L'Organisation internationale du Travail. Origine, développement, avenir, Rennes, Presses Universitaires de Rennes, 2011.

13 "Une SDN américaine", extracto de una carta de Fabra Ribas a Albert Thomas del 5 de agosto de 1922, Archivo oIT (АОIт), Catálogo de Albert Thomas (САT): 5-18-2 (en adelante AOIT, САT). 
estuvieron dispuestos a apoyar la creación de una SDN americana, ${ }^{14}$ estos informes de los funcionarios de la OIT alimentaron el imaginario de un continente donde el regionalismo asumía el protagonismo.

En los primeros contactos diplomáticos sobre una probable visita de Thomas a América del Sur se planteó la posibilidad de hacer coincidir ese viaje con la realización de la CP de 1923. Manuel Rivas Vicuña, representante chileno a la SDN, señaló a Thomas las dificultades en obtener una invitación oficial de la Conferencia:

Los Congresos panamericanos resultan de una organización ya antigua y sólo los representantes de los Estados forman parte. Parecería difícil el obtener una invitación para la OIT pues una consulta previa a todos los Estados de América y su aceptación unánime sería necesaria. Los Estados Unidos se opondrían muy probablemente y la iniciativa sería así rechazada. ${ }^{15}$

En todo caso, según Rivas Vicuña, si el viaje de Thomas coincidía con la realización de la Conferencia tendría la ocasión de reunirse con los delegados gubernamentales y realizar una propaganda de la ort. Como se sabe, problemas de agenda retardaron el viaje de Thomas hasta 1925. Posteriormente, Moisés Poblete Troncoso, en su calidad de funcionario chileno de la OIT, viajó en 1928 a la CP de La Habana, donde según sus propios informes habría logrado detener la creación de una oficina panamericana del trabajo. ${ }^{16}$

Si consideramos la lentitud de la orT en consolidar su presencia en América Latina y la crítica de algunos delegados a las conferencias internacionales del trabajo, en razón de la falta de reconocimiento de las particularidades regionales por parte de la institución de Ginebra, los gobiernos latinoamericanos comenzaron a encontrar en las CP un ámbito privilegiado de discusión sobre las problemáticas so-

\footnotetext{
${ }^{14}$ Yannick Wehrli, Créer et maintenir l'intérêt : la liaison entre le Secrétariat de la SDN et l'Amérique latine (1919-1929), memoria Universidad de Ginebra, 2003.

${ }^{15}$ Carta de Rivas Vicuña a Thomas, 14 de febrero de 1922, Aort, CAT: 1-25-11-1.

${ }^{16}$ En una nota a la División Administrativa de la oIт Poblete señala a propósito de la creación de esta oficina "tema que había sido propuesto a vi Conferencia panamericana de la Habana de 1928 a la cual fui en misión, y que felizmente fue dejado de lado a consecuencia de recorridos personales que yo mismo hice cerca de delegados amigos". Aort, P 2037, M. Poblete Troncoso.
} 
ciales del continente. Si las CP nacieron como instancias de discusión y de búsqueda de acuerdos para enfrentar de manera conjunta diversos temas, era cuestión de tiempo que incorporaran en sus agendas las temáticas de trabajo. De hecho, buscaron a partir de 1923 tener un rol de contrapartida regional a la acción de la orT. Sin embargo, este interés se enmarca en la importancia que las mismas conferencias de Ginebra habían adquirido, así como en las invitaciones dirigidas por los delegados sudamericanos a Albert Thomas para visitar la región. Así, cuando el delegado chileno a la CP de 1923, Agustín Edwards, recomendó la moción de incorporar en el futuro los problemas sociales justificó esa proposición por la existencia, desde la Conferencia del trabajo de Berlín de 1890, de un contexto internacional favorable al desarrollo de una legislación internacional del trabajo. ${ }^{17} \mathrm{La}$ CP de 1923 propuso la adopción de medidas destinadas a promover la armonía entre el capital y el trabajo, el establecimiento de seguros sociales y el mejoramiento de las condiciones de producción. ${ }^{18}$ Esas recomendaciones sobre el trabajo, así como la idea de que sus propuestas fuesen discutidas en las próximas $\mathrm{CP}$, demuestran el interés de los gobiernos de darle un punto de vista regional a los problemas laborales. Un ejemplo de esta toma de posición es la recomendación de promover convenciones entre los países americanos, garantizando normas generales de política económica y social o de reciprocidad en el tratamiento de los obreros.

La misma crisis de 1929, y sus efectos en la cesantía y la producción, relanzó la agenda social en los encuentros futuros, especialmente en la CP de 1933 realizada en Montevideo. Si hasta la crisis de 1929 el paradigma económico de América Latina era el liberalismo, con una economía abierta al comercio exterior y donde el crecimiento se apoyaba sobre la exportación de productos primarios, no sorprende que los efectos de la crisis fuesen tan fuertes en la región. ${ }^{19}$ Frente a la crisis económica, y sus efectos inesperados en el comercio

${ }^{17}$ Actas de las Sesiones plenarias de la Quinta Conferencia Internacional Americana, tomo II, vol. 2, Santiago, Imprenta Universitaria, 1925, 150.

${ }^{18}$ Ibid.

${ }^{19}$ Angus Maddison, Dos crisis: América y Asia. 1929-1938 y 1973-1983, México, FCE, 1988, 20. 
mundial, la OIT asumió desde el comienzo una posición clara, aunque no exenta de dilemas. La crisis de 1929 era la prueba de la necesidad de integrar al estudio de las políticas sociales la dimensión económica. Aunque después de su creación la ort buscó ampliar su dominio de acción, incorporando la discusión de temas como la organización científica del trabajo o los aspectos financieros, ${ }^{20}$ la crisis de 1929 obligó a un esfuerzo de coordinación entre las diversas instituciones y países como jamás se había visto, cuestionando su capacidad de enfrentar la crisis con las herramientas tradicionales: el sistema de recomendación y de convención.

El aspecto más visible de la crisis fue la cesantía de millones de personas, con lo cual gran parte de las medidas discutidas en las conferencias del trabajo de la época cruzaron esta problemática. Las proposiciones iniciales contempladas por la OIT fueron la coordinación de las bolsas de trabajo, la puesta en práctica de los sistemas de seguros de cesantía y la promoción de los trabajos públicos, todos estos aspectos eran parte del dominio no discutido de la institución de Ginebra. La falta de apoyo técnico y político impidió tomar decisiones más concretas en torno a las políticas económicas frente al aumento de la cesantía o la caída de la producción. ${ }^{21}$ Sin embargo, conforme los efectos de la crisis aumentaban, se tomaron posiciones más riesgosas en dominios que no eran los tradicionales. Así, la conferencia internacional del trabajo de 1932 aprobó una resolución recomendando la reducción de la jornada de trabajo y rechazando toda disminución de salarios. De esta manera, el ritmo de la producción podría elevarse en el nivel del consumo y el empleo podría ser distribuido a mayor número de trabajadores. ${ }^{22}$

${ }^{20}$ Thomas Cayet, "Le Bureau international du travail et la modernisation économique dans les années 1920: esquisse d'une dynamique institutionnelle", Travail et Emploi, núm. 110, abril-junio 2007, 15-25; Thomas Cayet, "Travailler à la marge: le Bureau international du travail et l'organisation scientifique du travail (1923-1933)", Le mouvement social, núm. 228, París, julio-septiembre 2009, 39-56.

${ }^{21}$ Jean-Michel Bonvin, L'Organisation internationale du travail..., op. cit., p. 35; Thomas Cayet, "Le 'Planning' comme organisation du travail? Une interrogation sur les études économiques du Bureau International du Travail dans les années 30”, en Isabel Lespinet-Moret y Vincent Viet, L'Organisation internationale du Travail. Origine, développement, avenir..., op. cit.

${ }^{22}$ Informations Sociales, núm. 6, 4 de mayo de 1932. 
A partir de 1933, la oit sostuvo la intervención de los Estados en materia económica, lo que abrió un fuerte debate sobre los dominios de acción de la institución de Ginebra. ${ }^{23}$ Claramente, la crisis de 1929 aparecía como un punto de inflexión en un movimiento mundial que marchaba hacia una nueva dirección y que exigía nuevas medidas. A propósito de ese contexto el director de la OIT, Harold Butler, señaló en la conferencia internacional del trabajo de 1933 que la reglamentación de las condiciones laborales no era tanto una cuestión de protección de los trabajadores, sino de organización racional de la sociedad. ${ }^{24}$

En todo caso, ¿la economía dirigida no había sido lo que había promovido la OIT en todos sus años de existencia? Toda legislación social constituía, según Butler, de una cierta forma, una injerencia en el libre juego de las fuerzas económicas, injerencia deliberada y dirigida hacia un objetivo social. La diferencia es que en el contexto de la crisis mundial las medidas aprobadas debían aplicarse en un marco internacional coordinado como jamás se había hecho antes: "Hasta el presente, todas las convenciones y recomendaciones han estado fundadas en experiencias realizadas sobre el plano nacional. El hecho que nosotros estemos obligados, en lo que concierne a la reducción de la jornada de trabajo, a tener, sobre el plano internacional, una nueva experiencia, aumenta la dificultad de ese problema". 25

El desarrollo de un sentimiento regionalista en los delegados a las conferencias internacionales del trabajo puede ser rastreado de forma explícita desde comienzos de los años treinta. Sin embargo, desde 1919, los representantes de los gobiernos danés, finlandés, noruego y sueco se habían reunido para estudiar los diferentes aspectos de la política social nacional e internacional. ${ }^{26}$ La conferencia de Londres, en marzo de 1926, que había reunido a las principales 1933

23 "Discussion du Rapport du Directeur", Informations Sociales, núm. 1, 3 de julio de

24 “Réponse du Directeur", Informations Sociales, núm. 1, 3 de julio de 1933, 39.

${ }^{25}$ Ibid., p. 38.

26 "La collaboration des pays du Nord dans le domaine social", Informations Sociales, núm. 9, 30 de agosto de 1926, 378-379. 
potencias industriales de Europa para debatir la ratificación de la convención sobre la limitación de la jornada de trabajo, es otro ejemplo. ${ }^{27}$ En la conferencia internacional del trabajo de 1926, el delegado gubernamental de Finlandia propuso una cooperación regional con el fin de avanzar eficazmente en la legislación social internacional. Esta propuesta se fundaba en que el campo de aplicación de las convenciones era muy amplio y, en consecuencia, imposible de poner en práctica en todas las naciones. La colaboración más estrecha entre un grupo de países que compartían las condiciones geográficas o económicas permitiría avanzar en las ratificaciones simultáneas. ${ }^{28}$

En las primeras conferencias del trabajo, los delegados de América del Sur manifestaron la necesidad de un acercamiento más directo de la institución de Ginebra a la realidad local, un aspecto que las modalidades de reunión anual no eran capaces de satisfacer, sea por la distancia o por la falta de tiempo. Si desde 1931 ciertas resoluciones demandaban la creación de conferencias continentales, especialmente asiática, ${ }^{29}$ en 1932 el delegado chileno, Saavedra-Aguero, había llamado la atención sobre la representación insuficiente de los países latinoamericanos en las instancias de la OIT $^{30}$ y en 1933 el delegado de Uruguay, De Castro, había planteado la necesidad de una política de colaboración más estrecha, deseando "que la reunión de los delegados de los países latinoamericanos, considerada por el director, de acuerdo con su Consejo de Administración, pudiese tener una mayor importancia en los ańos venideros" ${ }^{31}$ El director Harold Butler reconoció en su informe de 1934 la importancia asignada a los problemas sociales en el continente americano, recordando la resolución de la conferencia panamericana de 1933 que

${ }^{27}$ Informations Sociales, núm. 11, 15 de marzo de 1926. 1926,79 .

${ }^{28}$ SDN, Conférence Internationale du travail, Genève, 1926, vol. 1, Ginebra, BIT,

${ }^{29}$ La conferencia internacional del trabajo de 1931 adoptó una resolución favorable a una reunión de una conferencia asiática, la cual no se realizó, Luis Vilaza, Las conferencias interamericanas del trabajo, memoria de la Facultad de Ciencias Jurídicas de la Universidad de Chile, 1952.

${ }^{30}$ SDN, Conférence Internationale du Travail, Genève, 1932, Ginebra, BIT, 1932, 166.

${ }^{31}$ sDN, Conférence Internationale du Travail, Genève, 1933, Ginebra, BIT, 1933, 192. 
postulaba la creación del IIT. Así, se mostró abierto a la realización de una conferencia regional, pero a condición "de precisar lo que debe ser una cuestión regional y lo que debe ser una cuestión mundial" y sin afectar la acción universal de la OIT. ${ }^{32}$

Así, la apertura de la ort a tratar los problemas en el seno de las instancias regionales explicará la convocatoria a una primera Conferencia Americana del Trabajo en Santiago de Chile en 1936, conferencia que analizaremos más adelante. Por su parte, desde América Latina, los fundamentos estaban establecidos para la creación de una organización panamericana del trabajo, orientada a enfrentar las consecuencias sociales de la crisis económica.

\section{LA CONFERENCIA PANAMERICANA DE 1933}

Es en el debate sobre las consecuencias sociales y económicas de la crisis de 1929 que se desarrolla la VII CP de 1933 en Montevideo. Las proposiciones estuvieron orientadas a limitar el mercado de trabajo, a través de ciertas restricciones para hacer frente a la cesantía. A ello debía ayudar la puesta en práctica de planes de obras públicas fundados en el carácter reproductivo de ellos y, en consecuencia, capaces de disminuir los efectos sociales ocasionados por la cesantía. ${ }^{33}$ Además, se propuso la organización de colonias rurales con el fin de aumentar la producción agrícola y de paso enfrentar el problema de la inflación. Se propuso también la creación de agencias de empleo que entregaran información correcta sobre la situación del mercado laboral, que favorecieran el desplazamiento de los trabajadores hacia zonas de demanda de mano de obra. Finalmente, se propuso un seguro de cesantía, con un aporte del Estado o de las instituciones establecidas con ese fin. La discusión se concentró en torno a propuestas legislativas en materia de seguros de invalidez, de vejez y de muerte, y el desarrollo de cajas que ofrecieran una ayuda médica obligatoria a los asalariados de todas las ramas industriales. Sin embargo, una de las resoluciones más importantes de la CP de

${ }^{32}$ sDn, Conférence Internationale du Travail, Genève, 1934, Ginebra, BIT, 1934, 282.

${ }^{33}$ Vanesa Teitelbaum, "La política laboral en la vir conferencia panamericana...", $o p$. cit., 137. 
1933 fue la recomendación de crear un "Instituto Interamericano del Trabajo", que tendría su sede en Buenos Aires.

Aunque no hay antecedentes concretos sobre la creación de ese Instituto, ya en la vi CP de la Habana en 1928 se habría propuesto la creación de una "organización panamericana de trabajo". Sin embargo, la acción de algunos funcionarios de la orT habría evitado la discusión del tema. ${ }^{34}$ En la ocasión se habría solamente acordado recomendar al Comité Ejecutivo de la UPAM de incluir en la VII CP el estudio de los problemas relativos al mejoramiento de las condiciones de los trabajadores y de su estándar de vida en los países del continente. $^{35}$

La creación del Instituto fue propuesta por la delegación mexicana, quien además redactó el proyecto de constitución. En la época, México estaba comprometido en una política social que lo llevó a dictar la Ley Federal del Trabajo en 1931 y a ingresar a la oIT en el mismo año. ${ }^{36} \mathrm{El}$ Instituto Interamericano serviría como un instrumento de cooperación en materia de trabajo, reconociendo las particularidades del continente. ${ }^{37}$ Así, entre las consideraciones para su creación, estuvo la necesidad de promover políticas para mejorar la condición social y económica de los trabajadores, además de reconocer la necesidad de abordar los problemas sociales y de trabajo

${ }^{34}$ En una nota a la División Administrativa de la orT, Moisés Poblete señala a propósito de una organización panamericana del trabajo: "aspecto que había sido propuesto en la $6^{a}$ Conferencia Panamericana de la Habana de 1928 y que felizmente fue dejado de lado luego de acciones personales que yo mismo hice frente a los delegados amigos", AOIT, P 2037, M. Poblete Troncoso.

${ }^{35}$ Sexta Conferencia Internacional Americana, Acta Final. Mociones, acuerdos, resoluciones y convenciones, La Habana, Imprenta de Rambla, Bouza y Ca., 1928, 11.

${ }^{36}$ Sobre la política social mexicana de la época véase Michelle Dion, "The Political Origins of Social Security in Mexico during the Cárdenas and Ávila Camacho Administrations", Mexican Studies, vol. 21, invierno 2005, 59-95. Sobre el ingreso de México a la OIT, véase Fabián Herrera, "México y la organización Internacional del Trabajo: Los orígenes de una relación, 1919-1931”, Foro Internacional, núm. 204, abril-junio 2011, 336-355.

${ }^{37}$ Tal como señaló un informe de la delegación mexicana sobre este punto: "Pronto pudo evidenciarse que la creación de un Instituto Interamericano del Trabajo no sería una inútil duplicación de la Oficina de Ginebra, sino un valioso elemento de cooperación”, Manuel Sierra, México y la Conferencia de Montevideo, México, Imprenta de la Secretaría de Relaciones Exteriores, 1934, 31. 
desde una visión regional. En este punto se señaló que la creación del Instituto no atentaría contra la acción de la orT en la región, al contrario sería "una valiosa colaboración, luego de estudiar y de resolver los problemas sociales americanos que presentan aspectos diferentes, incluso antagónicos, de los europeos". ${ }^{38}$

El Instituto, en cuanto a su estructura, estaría compuesto por una Oficina y las Conferencias Interamericanas. También se resolvió que las facultades que tendrían las conferencias y los procedimientos de las convenciones serían reglamentadas en la próxima reunión de la cr. En cuanto al funcionamiento de los órganos directivos del Instituto, se eligió el sistema de representación y de igualdad de las delegaciones nacionales, que serían nombrados entre los representantes gubernamentales, patronales y sindicales, siguiendo el modelo de representación tripartita de la orT. El órgano ejecutivo de la Oficina Interamericana de Trabajo sería una Comisión elegida por el Consejo Directivo de la UPAM y formada por un representante patronal, uno sindical y otro gubernamental, propuesto por todos los países del continente. La Comisión debería nombrar el personal técnico miembro de la Oficina Interamericana, que se ocuparía de manera prioritaria de la recopilación de información para determinar las organizaciones sindicales y patronales, las más representativas de cada país, además de los estudios sobre el trabajo. ${ }^{39}$

Que la CP haya adoptado como tarea inmediata de la Comisión la recopilación de información para determinar las organizaciones más representativas de la región en el seno de la nueva institución, demuestra el interés de los delegados de promover instancias de participación regional, que respetasen realmente el principio de "representación auténtica”, el aspecto más problemático y difícil de resolver por las conferencias de la OIT. Como criterios de representatividad de la organización de trabajadores se consideró su presencia en la nación, su diversidad de grupos y su número. Del mismo modo se debía considerar en las organizaciones empresariales el nú-

${ }^{38}$ Unión Panamericana, Conferencias internacionales americanas, 1889-1936, Washington, Dotación Carnegie para la Paz Internacional, 1938, 495.

${ }^{39}$ Departamento del Trabajo, La obra social del presidente Rodríguez, México, Talleres Gráficos de La Nación, 1934. 
mero de empresas asociadas y la cantidad de trabajadores empleados. ${ }^{40}$ Que la implementación del Instituto Interamericano siguiera la estructura de la OIT muestra el rol de esta institución como referente en materia de trabajo. Ahora, que el espíritu de las resoluciones de la VII CP tuviera un tono conciliador, recalcando que la labor del Instituto sería de colaboración con la institución de Ginebra, también demuestra el interés de los delegados de no invadir un dominio particular de una institución internacional. Sin embargo, no todos los países de América Latina estuvieron de acuerdo con el espíritu que guió la creación del Instituto y con el interés de las CP en las temáticas del trabajo. La delegación de Venezuela, por ejemplo, expresó su rechazo a formar parte del Instituto, en atención a que el país había asumido un compromiso con la oIT y que las actividades del Instituto competían con su labor. ${ }^{41}$

Entre los objetivos más concretos del Instituto estaba la promoción de la convención interamericana para la igualdad de trato de los trabajadores contratados en países extranjeros. De conformidad con la resolución xxiıI del acta final, el Instituto debería garantizar, a través de recomendaciones o de convenciones, las condiciones de los trabajadores en los siguientes aspectos (véase cuadro 1).

El listado del cuadro 1 refleja una serie de aspectos que habían formado parte de la agenda legislativa de los gobiernos o al menos de sus preocupaciones. Los contratos colectivos, la jornada de ocho horas, la higiene de los lugares de producción, la construcción de habitaciones obreras, todo era parte de ese nivel primario de preocupaciones. Sin embargo, había otro dominio más interesante y nuevo de inquietudes. Por ejemplo, que el primer punto de las tareas asignadas al Instituto sea la libertad sindical se explica, al menos, por dos razones. Por un lado, durante los ańos treinta, el control de los sindicatos por los gobiernos, promoviendo organizaciones obreras favorables a sus intereses o simplemente eliminando esas organizaciones que no se adaptaban al nuevo orden de ideas, se transformó

${ }^{40}$ Unión Panamericana, Conferencias internacionales americanas..., op. cit., 497.

${ }^{41}$ Oficina de Información Obrera y Social, Resoluciones, acuerdos, recomendaciones y declaraciones de las conferencias internacionales americanas sobre problemas sociales, Washington, Unión Panamericana, 1945. 
Cuadro i. Instituto Interamericano del Trabajo

1. Libre asociación sindical.

3. Sistema de ahorro popular.

5. Igual remuneración sin distinción de sexo y de nacionalidad.

7. Protección del ingreso frente a cualquier forma de crédito o confiscación de bienes.

9. Jornada de trabajo de ocho horas y de seis para los menores de 18 ańos.

11. Medidas para evitar la cesantía.

13. Eliminación del trabajo infantil y protección de la mujer.

15. Formación cultural y técnica de los trabajadores.

17. Higiene de lugares insalubres.

19. Promoción de estudios, memorias y publicaciones comparativas sobre las condiciones de trabajo.

21. Formación de tribunales de conciliación y de arbitraje
2. Contratos colectivos de trabajo.

4. Salario mínimo.

6. Seguros de enfermedad, de accidentes, etcétera.

8. Seguro de vejez.

10. Construcción de habitaciones obreras.

12. Reconocimiento del principio que la máquina es un instrumento auxiliar del hombre.

14. Orientación profesional de la mujer.

16. Protección general contra las enfermedades generales y profesionales.

18. Estudios sobre los problemas del trabajo.

20. Creación de bolsas de trabajo.

Fuente: VII Conferencia Internacional Panamericana, Montevideo, Imprenta de J. Florense, 1933.

en tema de verdadera preocupación tanto en las conferencias internacionales de la oIT, como en las organizaciones obreras. Por otra parte, los delegados a la CP de 1933 comprendieron que la legitimidad del Instituto sería garantizada por el apoyo no solamente de los gobiernos y de los empresarios, sino, sobre todo, de los trabajadores. Por ello, era necesario promover la libertad sindical al interior de los países, permitiendo la autonomía de los sindicatos en su representación al Instituto.

La incorporación de las temáticas como la orientación profesional y la formación cultural y técnica de los trabajadores, daba 
cuenta de un nuevo nivel de desafío planteado por la crisis económica de 1929. La importación de las teorías en boga en los Estados Unidos, como la organización científica del trabajo, suponía pensar en términos modernos la relación industrial, organizando de una manera racional el mercado de trabajo y aumentando, con ello, la productividad.

Aunque el Instituto haya asumido como parte de sus funciones la promoción de estudios sobre las condiciones laborales, la iniciativa demostraba la existencia de un campo todavía más amplio de articulación de una red de intelectuales y de instituciones encargadas de estudiar el tema. De una manera indirecta, los delegados a la CP de 1933 ponían en el centro de la discusión el aspecto, quizás, peor evaluado de la oit en el continente: la falta de estudios de la institución de Ginebra. Ahora, el hecho que el Instituto promoviera modalidades concretas de conocimiento (como las memorias y los estudios comparativos, entre otros aspectos) permitía entender que el objetivo de los delegados era situar la producción de conocimiento en los propios países, pero bajo la coordinación y difusión del Instituto. Por último, la incorporación del punto número doce sobre el reconocimiento del principio que la máquina es la auxiliar del hombre en el proceso productivo era un guiño a las posiciones críticas del capitalismo, que comprendían grupos tan diversos como socialistas, socialdemócratas, corporativistas y socialcristianos, entre otros.

\section{OTRO CONTEXTO: LA OPOSICIÓN DE I936}

En 1934, los Estados-Unidos ingresaron a la oit, lo que supuso un golpe a los esfuerzos desplegados hasta el momento de crear, por una parte, un bloque político regional competidor de la SDN y, por otra, un Instituto de Trabajo en el seno de la UPAM. En 1936, las organizaciones obreras dieron un golpe de gracia a esta última idea, reafirmando su apoyo a la acción de la institución de Ginebra.

En 1936 se realizó en Santiago de Chile lo que puede ser considerada la primera conferencia regional del trabajo. Propuesta por el delegado chileno a la Conferencia Internacional de 1935, fue aprobada por el Consejo de Administración de la orT en consideración 
de que sería una instancia de encuentro y de colaboración de los distintos actores que participaban en la red de la OIт. ${ }^{42}$

En el curso de esta conferencia los trabajadores manifestaron su rechazo a la creación de cualquier organización laboral de origen panamericano. Es necesario recordar que el consejero técnico del gobierno uruguayo había solicitado discutir la creación de un organismo regional del trabajo. Su objetivo sería la coordinación de los organismos técnicos con los organismos sindicales, a fin de desarrollar una acción continental en favor de la ratificación de las convenciones internacionales. Ideas similares habían sido expresadas por el delegado gubernamental uruguayo, Dr. Antuña. ${ }^{43}$ El delegado paraguayo también había manifestado su apoyo a la creación de un Instituto del Trabajo, que "sería un organismo regulador y de estudio de los problemas americanos del trabajo, de conexión y colaboración con la Oficina Internacional del Trabajo de Ginebra, cuya obra humanitaria y grande merece el homenaje de gratitud de todos los hombres trabajadores del mundo". ${ }^{44}$

El responsable de expresar la posición obrera en la conferencia fue el delegado chileno Luis Solís. Sus opiniones críticas dan cuenta de la toma de posición del conjunto del movimiento obrero latinoamericano. En concreto, Luis Solís cuestionó los avances de la legislación social chilena, denunciando el incumplimiento de las disposiciones sobre la jornada de ocho horas, la protección a la maternidad obrera y al trabajo de menores y, en fin, la falta de aplicación de esas leyes en la agricultura. Además, demandó una mayor libertad de asociación, la eliminación de la tutela del Estado sobre los sindicatos y poner fin a los obstáculos en la formación de federaciones sindicales. ${ }^{45} \mathrm{El}$ delegado obrero proponía una nueva política de previsión social, aumentando el aporte patronal y elevando los salarios y la reducción del costo de la vida, que había aumentado

\footnotetext{
${ }^{42} \mathrm{Al}$ respecto véase la colaboración de Patricio Herrera sobre las conferencias regionales en esta misma sección temática.

${ }^{43}$ Conferencia del trabajo de los Estados de América miembros de la Organización Internacional del Trabajo, Acta de las sesiones, OIT, Ginebra, 1936.

${ }^{44}$ Ibid., 127.

${ }^{45}$ Ibid.
} 
$60 \%$ entre 1932 y 1936 . Una consideración especial tenían los campesinos, los que estaban excluidos de las políticas sociales, incluso de las investigaciones. ${ }^{46} \mathrm{El}$ delegado chileno Luis Solís criticó la falta de representación obrera en las conferencias del trabajo en contradicción con sus propios reglamentos. Sin embargo, manifestó su apoyo al trabajo de la oIT por la utilidad que prestaba a la acción obrera, tanto como instrumento de investigaciones sociales o como tribuna de resonancia internacional para los trabajadores. ${ }^{47}$

En cuanto al tema que nos ocupa en este escrito, Solís también rechazó la creación de un organismo panamericano del trabajo. Tal opción se apoyaba en una constatación simple: los factores geográficos e históricos habían dejado de tener un rol en la elaboración del Derecho. Solís señalaba que más allá de esos factores se había desarrollado la "superestructura técnica del capitalismo", que suprime las diferencias territoriales, que acorta las distancias y que acentúa la interdependencia de los países en el plano mundial. ${ }^{48}$ Sin embargo, comprendía la necesidad de comprometer todavía más a los trabajadores en las actividades de la OIT, garantizando su representación, en particular en el trabajo de inspección:

la institución de Ginebra es buena para nosotros en la medida que sea controlada por los trabajadores. Un organismo internacional de tipo exclusivamente gubernamental, o que sea solamente controlada por falsos obreros, productos artificiales de los dictadores latinoamericanos, no ofrece para nosotros la garantía mínima. ${ }^{49}$

Ahora, para desarrollar esta función era fundamental organizar el movimiento de trabajadores en el plano continental. Si el progreso en la organización de los sindicatos nacionales era evidente, el delegado obrero chileno demandó la unidad del movimiento sindical de América Latina:

${ }^{46}$ Ibid., 64.
${ }^{47}$ Ibid., 66.
${ }^{48}$ Ibid., 67.
${ }^{49}$ Ibid., 68. 
Permitidme todavía, señores delegados, rebalsando los muros de esta sala, hacer desde su tribuna un llamado ferviente y caluroso a los trabajadores explotados del país, del continente y del mundo, a unirse férreamente en torno a sus intereses específicos de clase. A su servicio está la Confederación Nacional de Sindicatos de Chile, cuya Secretaría me honra, y la Central Sindical única, en formación. ${ }^{50}$

La formación obrera acogía de manera favorable la proposición formulada por la representación sindical del Consejo de Administración del BIT, de formar parte de la Federación Sindical Internacional, pero abandonando las tácticas de colaboración de clases que habían facilitado, de acuerdo al delegado obrero chileno, el avance del fascismo en Europa. La lucha contra el fascismo debía ser entonces la base del acercamiento de los trabajadores en vista de la construcción de un régimen social y económico, fundado sobre la socialización de los medios de producción y de una democracia "efectiva”, es decir, una "democracia proletaria". Así, en definitiva, la conferencia regional debía ser una caja de resonancia de los problemas sociales y la instancia de colaboración en la organización de un movimiento obrero continental. ${ }^{51}$

Esta toma de posición del movimiento obrero en la Conferencia de 1936 en Santiago de Chile, se explica al menos por dos razones. En primer lugar, el interés en apoyar la acción de la oIT y de rechazar la creación de un organismo panamericano del trabajo expresan los temores de la dirección obrera de que ese organismo fuese la antesala de la intervención norteamericana en los intereses obreros de la región, reformulando la experiencia fracasada de la Confederación Obrera Panamericana (COPA) $)^{52}$ Los trabajadores no ignoraban la necesidad de formular una perspectiva regional en el análisis de los problemas latinoamericanos, promoviendo estudios y políticas sociales para el continente, pero consideraban que la apertura de la OIT para convocar una conferencia regional era un paso muy importante en el rol que debía tener la región en la formulación de políticas

\footnotetext{
${ }^{50}$ Ibid., 66.

${ }^{51}$ Ibid., 108-109.

${ }^{52}$ Robert Alexander, Labor Parties of Latin American, Nueva York, L.F.I.D., 1942.
} 
sociales. En segundo lugar, la transformación del discurso revolucionario de la dirección obrera de la América Latina daba cuenta de la presencia de nuevos vientos que soplaban en el mundo. Los llamados a luchar contra el fascismo, a construir una "democracia proletaria" y a defender los avances sociales y económicos ganados, serían objetivos mejor cumplidos si se reforzaba la alianza obrera con la orT en detrimento de la nueva experiencia panamericana.

Consecuente con las preocupaciones principales del movimiento obrero representado en la Conferencia regional de 1936, los delegados obreros propusieron resoluciones de diferente tipo: creación de ministerios del trabajo; creación o perfeccionamiento de los servicios centrales de estadísticas sociales, especialmente en lo que concierne los salarios, el costo de la vida, la cesantía, los accidentes del trabajo, entre otros; medidas de protección a la población indígena; el desarrollo sistemático de planes de obras públicas destinados a combatir la cesantía; y la ampliación de los seguros sociales a todos los trabajadores y especialmente a los trabajadores agrícolas. ${ }^{53}$

Sin embargo, dos resoluciones expresan de una manera indudable la nueva etapa de relaciones entre el movimiento obrero y la orT. En primer lugar, el llamado a la creación de federaciones centrales de patrones y obreros para facilitar la participación de esas organizaciones en las actividades de Ginebra y, en segundo lugar, el llamado a sostener su acción en el continente a través del aumento de los funcionarios latinoamericanos del BIT, el aumento de las publicaciones en espańol y la continuación de las conferencias regionales del trabajo. ${ }^{54}$

Los representantes de los gobiernos en la conferencia de Santiago de Chile no estuvieron en condición de defender el proyecto de creación de un Instituto del Trabajo tal como lo habían hecho en 1933. El contexto latinoamericano había cambiado. En primer lugar, se notaba una lenta, pero sostenida, recuperación de la economía y los debates sobre la necesidad de enfrentar la realidad social y laboral del continente no se hicieron desde la urgencia de una recu-

${ }^{53}$ Ibid., 145-148.

${ }^{54}$ Ibid., 144. 
peración económica a cualquier precio. En segundo lugar, la política exterior norteamericana había cambiado desde el arribo de Roosevelt al poder, con la puesta en práctica de la llamada política del "buen vecino" a partir de 1933. Además, con su ingreso a la ort el año 1934, Estados Unidos buscaba iniciar una nueva etapa en su política exterior.

A diferencia de la CP de 1933, las resoluciones de la Conferencia de 1936 no hicieron ninguna referencia a la creación de un Instituto del Trabajo. Un informe sometido al Consejo Directivo de la UPAM, sobre los avances en el cumplimiento de las resoluciones adoptadas en la VII CP de Montevideo, mostraba la decepción por el desinterés demostrado por el gobierno argentino en el nombramiento de una comisión organizadora para gestionar su creación. ${ }^{55}$ En 1936, el Instituto se había transformado en un proyecto que debía ser archivado.

\section{Tres consideraciones finales. Primero:} UNA HISTORIA INCONCLUSA

Desde comienzos de la década de 1920 se había planteado la necesidad de abordar los problemas sociales desde un punto de vista regional. Así, las instancias panamericanas ofrecieron la posibilidad de tratar aspectos claves para la integración del continente. En 1923 se inauguró la política de declaraciones de las CP en orden a debatir problemas sociales y en 1933 se propuso, en la misma instancia, la creación de un Instituto del Trabajo. Sus estructuras y funciones serían similares a la OIT, con lo cual se invadía su dominio de acción y de paso se colocaba en riesgo el apoyo de una región clave en su política de internacionalización.

Sin embargo, la etapa de ratificaciones de las convenciones del trabajo de parte de algunos países entre 1933 y 1934 contribuyó, por una parte, a moderar las críticas de los países europeos sobre el poco compromiso de los países en materia de legislación social universal y, por otra, a sostener los sectores que veían en América Latina

${ }^{55}$ Unión Panamericana, Medidas adoptadas por la Unión Panamericana en cumplimiento de las convenciones suscritas y resoluciones aprobadas por la séptima conferencia internacional americana, Washington, Unión Panamericana, 1936, 24. 
un aliado clave en el fortalecimiento de la OIT. En fin, es necesario considerar que, a partir de la crisis de 1930, los países de la región fueron confrontados a una serie de problemas, como la cesantía y la ausencia de seguros sociales, que obligaron a los gobiernos a solicitar la ayuda técnica de la organización de Ginebra en la realización de estudios y de asesorías. Esos mismos actores (gobiernos, trabajadores e instituciones), que en 1933 estaban dispuestos a apoyar la creación de un Instituto del Trabajo, habían cambiado su posición hacia 1936, siguiendo los nuevos vientos que soplaban en el continente. La convocatoria de una conferencia regional en Santiago de Chile, el cambio de clima político en los Estados Unidos, con su incorporación en 1934 a la OIT, y la falta de apoyo de gobiernos y de trabajadores hicieron inviable el Instituto.

Lo que muestra este desconocido capítulo de las relaciones entre la oIT y América Latina es que estuvo pleno de malos entendidos. El Instituto puede ser considerado un arma de presión de algunos países para reforzar el bloque regional frente a la SDN, presión que sólo podía funcionar mientras no existieran espacios de discusión sobre los problemas sociales y laborales del continente. Con el ingreso de los Estados Unidos a la oIT y la apertura a convocar una conferencia regional, la creación del Instituto perdía todo interés. Así, hacia 1936, sin el apoyo político de la UPAM, incluso económico de los Estados Unidos, el Instituto era inviable. Concretamente, ¿por qué apoyar la creación de una nueva agencia regional del trabajo si existía ya una en Ginebra, con un personal capacitado y dispuesta a promover mayor acercamiento con la región? El buen sentido y la economía de recursos se habían impuesto al sueño de una institución panamericana del trabajo con sede en Buenos Aires.

\section{SEgundo: UnA HISTORIA REVELADA}

Una historia como la del Instituto del Trabajo nos ofrece la posibilidad de discutir sobre la pertinencia de estudiar procesos históricos que en una primera mirada parecieran no conducir a ninguna parte. Si el Instituto fue un proyecto que no llegó a buen término ¿en qué radica su interés desde un punto de vista historiográfico? 
Lo que nos revela esta historia inconclusa es la importancia que tenía el continente en el contexto de las relaciones internacionales. América Latina aparecía modelada a partir de un universo de disputas globales promovidas por la Sociedad de Naciones, los Estados Unidos y las instituciones satelitales del orden mundial posterior a la Primera Guerra Mundial. Si las CP comenzaron a promover la discusión de materias sociales y laborales se explica tanto por la importancia que esos aspectos comenzaban a tener desde un punto de vista regional como por la ausencia de un verdadero debate latinoamericano sobre la cuestión social. Hay que recordar que la acción de la OIT en el continente era muy débil en los primeros ańos de la década de 1920. Lentamente fue contratando funcionarios de origen latinoamericano y estableciendo corresponsales en los países. Así en el cruce de las necesidades de los Estados Unidos de asegurar su presencia en una región importante desde un punto de vista político y económico, y de la necesidad de los países latinoamericanos de reconocimiento de sus particularidades, la OIT se vio obligada a acelerar el proceso de acercamiento a América Latina, hasta convocar una primera conferencia regional en 1936. La posición de los trabajadores frente al proyecto de creación del Instituto debe ser explicado por su disposición a formar parte de las instancias de debate regional, pero lejos del control norteamericano. Tal como señaló el delegado obrero en la Conferencia regional de 1936, la disposición de los trabajadores para promover instancias de discusión regional debía entenderse en el marco de las competencias técnicas de la OIT.

\section{TERCERO: UNA HISTORIA REPENSADA}

La historia del Instituto del Trabajo nos ayuda a repensar el Estado de Bienestar, evaluando si los análisis ofrecidos hasta el momento son los adecuados o si han pecado de cierto reduccionismo. El Estado de Bienestar ha sido comprendido a partir de enfoques estrictamente nacionales, que ponen en juego los intereses y conflictos que enfrentan a distintos grupos. Bajo la lógica corporativa, las políticas sociales serían cooptadas (tanto en su promoción como en sus efec- 
tos prácticos) por la presencia de distintos sectores representados en el interior del Estado, el cual tiene una autonomía relativa de las estructuras sociales y económicas, y cumpliría la función de construir un consenso básico para la acumulación capitalista. Si bien, estos análisis son aún pertinentes, no incorporan la dimensión continental y el rol jugado por las instancias regionales en la formación de las políticas sociales. Tal como lo presentamos someramente en este estudio, las CP y la conferencia regional promovida por la OIT en 1936, ofrecieron debates interesantes sobre la promoción de políticas, programas y estándares en materia laboral y seguros sociales, donde actuaron las elites (sindicales, empresariales y gubernamentales) con representación internacional, y reconocidas por su capacidad técnica.

\section{ArCHIVOS}

Archivo Oficina Internacional del Trabajo.

Catalogo Albert Thomas: Dossier, M. Poblete Troncoso, P 2037.

Catálogo Albert Thomas: 5-18-2.

Catálogo Albert Thomas: 1-25-11-1.

HeMEROGRAFÍA

Informations Sociales, Ginebra.

\section{FUENTES IMPRESAS}

Actas y documentos. Segunda Conferencia Panamericana, México, Tipografía de la Oficina Impresora de Estampillas, 1902. Actas de las Sesiones plenarias de la Quinta Conferencia Internacional Americana, Santiago, Imprenta Universitaria, 1925, tomo II, vol. 2.

Alexander, Robert, Labor Parties of Latin American, Nueva York, L.F.I.D., 1942.

Conferencia del trabajo de los Estados de América miembros de la Organización Internacional del Trabajo, Acta de las sesiones, OIT, Ginebra, 1936. 
Departamento del Trabajo, La obra social del Presidente Rodriguez, México, Talleres Gráficos de La Nación, 1934.

Oficina de Información Obrera y Social, Resoluciones, acuerdos, recomendaciones y declaraciones de las conferencias internacionales americanas sobre problemas sociales, Washington, Unión Panamericana, 1945.

Quesada, Ernesto, Le evolución del panamericanismo, Buenos Aires, Talleres Gráficos del Ministerio de Agricultura de la Nación, 1919. sDN, Conférence Internationale du travail, Genève, 1926, vol. 1, Ginebra, BIT, 1926.

sDn, Conférence Internationale du Travail, Genève, 1932, Ginebra, BIT, 1932.

sDn, Conférence Internationale du Travail, Genève, 1933, Ginebra, BIT, 1933.

sDn, Conférence Internationale du Travail, Genève, 1934, Ginebra, BIT, 1934.

Sexta Conferencia Internacional Americana, Acta Final. Mociones, acuerdos, resoluciones y convenciones, La Habana, Imprenta de Rambla, Bouza y Ca., 1928.

Sierra, Manuel, México y la Conferencia de Montevideo, México, Imprenta de la Secretaría de Relaciones Exteriores, 1934.

Unión Panamericana, Medidas adoptadas por la Unión Panamericana en cumplimiento de las convenciones suscritas y resoluciones aprobadas por la séptima conferencia internacional americana, Washington, Unión Panamericana, 1936.

Unión Panamericana, Conferencias internacionales americanas, 1889-1936, Washington, Dotación Carnegie para la Paz internacional, 1938.

\section{LIBROS}

Aglan, Alya, Olivier Feiertag y Dzovinar Kévonian, dir., Humaniser le travail. Régimes économiques, régimes politiques et Organisation internationale du travail (1929-1969), Bruxelles, Peter Lang, 2011.

Bonvin, Jean-Michel, L'Organisation internationale du travail, París, PUF, 1998. 
Bulmer-Thomas, Víctor, "Las economías latinoamericanas, 19291939", en Leslie Bethell, Historia de América Latina, vol. 11, capítulo 1, Barcelona, Editorial Crítica, 1997.

, La historia económica de América Latina desde la independencia, México, FCE, 1998.

CAYet, Thomas, "Le Bureau international du travail et la modernisation économique dans les années 1920: esquisse d'une dynamique institutionnelle", Travail et Emploi, núm. 110, abril-junio 2007.

"Travailler à la marge : le Bureau international du travail et l'organisation scientifique du travail (1923-1933)", Le mouvement social, núm. 228, París, julio-septiembre 2009.

DAELE, Jasmien Van y otros, ILO Histories : Essays on the International Labour Organization and Its Impact on the World during the Twentieth Century, Berne, Peter Lang, 2010.

DAlleK, Robert, Franklin D. Roosevelt and American Foreign Policy, 1932-1945, Nueva York, Oxford University Press, 1995.

Dion, Michelle, "The Political Origins of Social Security in Mexico during the Cárdenas and Ávila Camacho Administrations", Mexican Studies, vol. 21, invierno 2005.

Fernández, Miguel Ángel, "I Conferencia Panamericana (Washington, 1889-1890). Prolegómenos para un Derecho Internacional Americano", en Carlos Marichal, México y las Conferencias Panamericanas, México, Secretaría de Relaciones Exteriores, 2002.

Fremann SMith, Robert, "América Latina, los Estados Unidos y las potencias europeas, 1830-1930", en Leslie Bethell, Historia de América Latina, vol. 7, capítulo 3, Barcelona, Editorial Crítica, 1991.

Gellman, Irwin F., Good Neighbor Diplomacy: United States Policies in Latin America, 1933-1945, Baltimore, John Hopkins University Press, 1979.

Herrera, Fabián, "México y la organización Internacional del Trabajo: Los orígenes de una relación, 1919-1931”, Foro Internacional, núm. 204, abril-junio 2011.

Котт, Sandrine, "Les organisations internationales, terrains d'étude de la globalisation. Jalons pour une approche socio-historique", Critique Internationale, núm. 52, marzo 2011. 
Maddison, Angus, Dos crisis: América y Asia. 1929-1938 y 19731983, México, FCE, 1988.

Rodgers, Gerry, Lee Swepston, Eddy Lee y Jasmien van Daele, L'orT et la quête de justice sociale, 1919-2009, Ginebra, OIT, 2009. Rosental, Paul-André, "Géopolitique et État-Providence. Le BIT et la politique mondiale des migrations dans l'entre-deux-guerres", Annales. Histoire, Sciences Sociales, núm. 1, 2006.

Teitelbaum, Vanesa, "La política laboral en la vir conferencia panamericana”, en Carlos Marichal, México y las Conferencias Panamericanas, México, Secretaría de Relaciones Exteriores, 2002.

VILAZA, Luis, Las conferencias interamericanas del trabajo, Memoria de la Facultad de Ciencias Jurídicas de la Universidad de Chile, 1952.

WeHrl, Yannick, Créer et maintenir l'intérêt : la liaison entre le Secrétariat de la SDN et l'Amérique latine (1919-1929), memoria Universidad de Ginebra, 2003.

Wehrl, Yannick y Fabián Herrera, “Le BIt et l'Amérique Latine durant l'entre-deux-guerres : problèmes et enjeux", en Isabel Lespinet-Moret y Vincent Viet, L'Organisation internationale du Travail. Origine, développement, avenir, Rennes, Presses Universitaires de Rennes, 2011.

FECHA DE RECEPCiÓn DEL ARTí́culo: 22 de agosto de 2012

FECHA DE APROBACIÓN: 12 de noviembre de 2012

FECHA DE RECEPCIÓN DE LA VERSIÓN FINAL: 19 de marzo de 2013 